\title{
Perancangan Kunci Public RSA dan ElGamal pada Kriptografi untuk Kemananan Informasi
}

\section{RSA and EIGamal Public Key Design on Cryptography for Information Security}

\author{
Susilawati * \\ Universitas Medan Area
}

*E-mail Korespondensi: susi.shilawati@gmail.com

\begin{abstract}
Abstrak
The use of very large primes in public key cryptography is necessary to avoid unauthorized decryption of messages. In its implementation, the generation of large prime numbers is constrained on the operation of the powers with large numbers. This paper discusses the technique of generating very large numbers using Linear Congruential Generator (LCG) algorithms and probabilistic prime number testing using the Miller-Rabin algorithm. The prime numbers generated are tested and analyzed on RSA and ElGamal public key cryptosystems for the purpose of information security.
\end{abstract}

Kata Kunci: Linear Congruential Generator (LCG), Miller-Rabin, RSA, ElGamal.

\begin{abstract}
The use of very large primes in public key cryptography is necessary to avoid unauthorized decryption of plaintext. In the implementation, the generation of large prime numbers is constrained on the operation of the powers with large numbers. This paper discusses the technique of generating very large numbers using Linear Congruential Generator (LCG) algorithms and probabilistic prime number testing using the Miller-Rabin algorithm. The prime numbers generated are tested and analyzed on the RSA and ElGamal public key cryptosystems for the purpose of information security.
\end{abstract}

Keywords: Linear Congruential Generator (LCG), Miller-Rabin, RSA, ElGamal 


\section{PENDAHULUAN}

Kriptografi merupakan teknik menyandikan pesan yang memanfaatkan ilmu matematika diantaranya adalah bilangan prima dengan segala sifat bilangan bulatnya seperti aritmatika modulo, perpangkatan, faktor persekutuan terbesar dan faktor kuadrat.

Teori bilangan (Number Theory) merupakan teori mendasar dalam memahami kriptografi. khususnya pada sistem kriptografi dengan kunci asimetrik atau kriptografi kunci publik. Sebagian besar kriptografi kunci publik menggunakan bilangan prima sebagai parameternya. Bilangan prima yang disarankan adalah bilangan prima yang berukuran besar yakni yang terdiri dari lebih dari seratus angka.

Makalah ini membahas tentang pembangkitan bilangan acak menggunakan algoritma Linear Congruential Generator (LCG), pengujian keprimaan bilangan menggunakan algoritma Miller-Rabin dan implementasi kriptografinya menggunakan algoritma RSA dan ElGamal.

\section{HASII DAN PEMBAHASAN}

\section{Linear Congruential Generator}

Bilangan acak (random) banyak digunakan dalam kriptografi kunci publik sebagai pembangkit parameter kunci, tujuannya agar bilangan tidak mudah diprediksi. Tidak ada prosedur komputasi yang benar-benar menghasilkan deret bilangan acak secara sempurna. Bilangan acak yang dihasilkan dengan rumus-rumus matematika adalah bilangan acak semu (pseudo), karena pembangkitan bilangannya dapat diulang kembali secara periodik. Pembangkitan seperti ini disebut pseudo-random number generator (PRNG).

Metode pembangkitan bilangan acak yang paling umum digunakan adalah
Linear Congruential Generator (LCG). LCG merupakan pembangkit bilangan acak yang sederhana dan mudah untuk diimplementasikan. LCG didefinisikan dalam bentuk berikut :

$$
X_{n}=\left(a X_{n-1}+b\right) \bmod m
$$

dimana :

$\mathrm{X}_{\mathrm{n}}=$ bilangan acak ke-n dari deretnya

$\mathrm{X}_{\mathrm{n}-1}=$ bilangan acak sebelumnya

$\mathrm{a}=$ faktor pengali

$\mathrm{b}=$ increment

$\mathrm{m}=$ modulus

$(a, b$, dan $m$ adalah konstan)

Persamaan (1) memiliki nilai awal $\mathrm{X}_{0}$ sebagai kunci pembangkit (seed). LCG mempunyai periode tidak lebih besar dari m, dan pada kebanyakan kasus periodenya kurang dari itu. LCG mempunyai periode penuh $(m-1)$ jika memenuhi syarat berikut:

1. $b$ relatif prima terhadap $m$.

2. $a-1$ dapat dibagi dengan semua faktor prima dari $m$.

3. $a-1$ kelipatan 4 jika $m$ juga kelipatan 4.

4. $m>\operatorname{maks}\left(a, b, X_{0}\right)$.

5. $a>0, b>0$.

Misalnya nilai-nilai untuk :

$\mathrm{X}_{\mathrm{n}} \leftarrow \mathrm{a}=11, \mathrm{~b}=17, \mathrm{~m}=23$ dan $\mathrm{X}_{0}=0$

Maka akan didapat rumusan sebagai berikut:

$$
X_{n}=\left(11 X_{n-1}+17\right) \bmod 23
$$

Kemudian dihitung nilai $X_{n}$ seperti dapat dilihat pada tabel 1.

\begin{tabular}{|c|c|}
\hline $\mathrm{n}$ & $\mathrm{X}_{\mathrm{n}}$ \\
\hline 1 & 17 \\
\hline 2 & 20 \\
\hline 3 & 7 \\
\hline 4 & 2 \\
\hline 5 & 16 \\
\hline 6 & 9 \\
\hline 7 & 1 \\
\hline 8 & 5 \\
\hline
\end{tabular}




\begin{tabular}{|c|c|}
\hline 9 & 3 \\
\hline 10 & 4 \\
\hline 11 & 15 \\
\hline 12 & 21 \\
\hline 13 & 18 \\
\hline 14 & 8 \\
\hline 15 & 13 \\
\hline 16 & 22 \\
\hline 17 & 6 \\
\hline 18 & 14 \\
\hline 19 & 10 \\
\hline 20 & 12 \\
\hline 21 & 11 \\
\hline 22 & 0 \\
\hline 23 & 17 \\
\hline 24 & 20 \\
\hline
\end{tabular}

Tabel 1. Rangkaian bilangan acak $n$ dan $X_{n}$ untuk $a=11, b=17, m=23$ dan $X 0=0$

Dari tabel 1 tampak bahwa barisan bilangan berulang pada $n=23$. Ini membuktikan bahwa bilangan acak semu memiliki suatu periode tertentu dan akan kembali ke keadaan awal setelah periode terlewati.

LCG memiliki keunggulan lebih cepat dan membutuhkan sedikit operasi bit dibandingkan dengan pembangkit bilangan semu lainnya. Kekurangan LCG terletak pada ketidakcocokannya bila digunakan untuk kriptografi karena bilangan acak yang dihasilkan dapat dengan mudah diprediksi urutan kemunculannya. Secara teoritis LCG mampu menghasilkan bilangan acak dengan baik, hal ini sangat sensitif terhadap pemilihan nilai-nilai $a, b$ dan $m$. Pemilihan nilai-nilai yang buruk dapat mengarah pada implementasi LCG yang tidak efisien. Tabel 2 menyajikan nilai konstanta yang baik untuk LCG berdasarkan hasil analisis.

\begin{tabular}{|l|l|l|}
\hline \multicolumn{1}{|c|}{$\mathbf{A}$} & \multicolumn{1}{c|}{$\mathbf{B}$} & \multicolumn{1}{c|}{$\mathbf{M}$} \\
\hline 106 & 1283 & 6075 \\
\hline 211 & 1663 & 7875 \\
\hline 421 & 1663 & 7875 \\
\hline 430 & 2351 & 11979 \\
\hline 936 & 1399 & 6655 \\
\hline
\end{tabular}

\begin{tabular}{|l|l|l|}
\hline 1366 & 1283 & 6075 \\
\hline 171 & 11213 & 53125 \\
\hline 859 & 2531 & 11979 \\
\hline 419 & 6173 & 29282 \\
\hline 967 & 3041 & 14406 \\
\hline 141 & 28411 & 134456 \\
\hline 625 & 6571 & 31104 \\
\hline 1541 & 2957 & 14000 \\
\hline 1741 & 2731 & 12960 \\
\hline 1291 & 4621 & 21870 \\
\hline 205 & 29573 & 139968 \\
\hline 421 & 17117 & 81000 \\
\hline 1255 & 6173 & 29282 \\
\hline 281 & 284111 & 134456 \\
\hline
\end{tabular}

Tabel 2. Konstanta baik untuk implementasi LCG

\section{Miller-Rabin}

Pada beberapa sistem kriptografi kunci publik dibutuhkan fungsi untuk memilih bilangan prima. Persoalannya adalah bagaimana algoritma menguji keprimaan suatu bilangan integer. Ada 2 algoritma pengujian bilangan prima yakni pengujian bersifat deterministik (pasti) dan pengujian bersifat probabilistik. Algoritma pengujian bersifat deterministik secara pasti menyatakan suatu bilangan integer termasuk bilangan prima atau bukan. Sedangkan algoritma pengujian bersifat probabilistik hanya memberikan status keprimaan suatu bilangan integer dengan nilai probabilitas. Algoritma pengujian yang banyak dipakai dalam sistem kriptografi adalah algoritma probabilistik Miller-Rabin. Algoritma ini memiliki 2 keunggulan yakni ringan dalam komputasi dan nilai probabilitas yang dihasilkan tinggi.

Algoritma Rabin-Miller untuk pengujian keprimaan

Input : $(n, a)\{n$ adalah bilangan integer positif dan $a$ adalah basis\}

Output : Status keprimaan $n$ dengan probabilitas $3 / 4$

Temukan $m$ dan $k$ sehingga $n-1=m \times 2^{k}$

$T=a^{m} \bmod n$

If $T= \pm 1$ then 
End if

return "Mungkin Bilangan Prima"

$$
\begin{aligned}
& \text { For } i=1 \rightarrow k-1 \text { do } \\
& T=T^{2} \bmod n \\
& \text { If } T=+1 \text { then } \\
& \text { End if } \\
& \text { return "Bilangan Komposit" } \\
& \text { If } T=-1 \text { then } \\
& \text { return"Mungkin Bilangan } \\
& \text { End if } \\
& \text { return "Bilangan Komposit" }
\end{aligned}
$$

\section{Perancangan Kunci Publik}

Kriptografi kunci publik atau sering juga disebut sebagai kriptografi kunci asimetrik pertama kali diusulkan oleh Deffie dan Hellman pada tahun 1976, yang memungkinkan pengguna berkomunikasi secara aman tanpa perlu berbagi kunci rahasia. Dikatakan kriptografi kunci publik, karena kunci untuk enkripsi bersifat publik sehingga dapat diketahui oleh siapapun, sedangkan kunci untuk dekripsi bersifat rahasia karena hanya diketahui oleh penerima pesan.

Sistem kriptografi kunci-publik yang aman memiliki dua karakteristik sebagai berikut :

1. Komputasi untuk enkripsi dan dekripsi pesan mudah dilakukan

2. Secara komputasi hampir tidak mungkin menurunkan kunci privat, yang disimbolkan dengan $d$, bila diketahui kunci publik yang disimbolkan dengan $e$, pasangannya.

Dua permasalahan matematis yang sering dijadikan dasar perancangan sepasang kunci pada kriptografi kunci publik adalah pemfaktoran, tujuan dilakukannya pemfaktoran adalah untuk memperoleh kunci privat. Contoh algoritma kriptografi yang menggunakan prinsip ini adalah RSA. Kesulitan RSA terletak pada pemfaktorkan bilangan yang besar menjadi faktor-faktor prima. Selain pemfaktoran, permasalahan berikutnya adalah logaritma diskrit, hal ini ditemukan pada algoritma kriptografi ElGamal.

\section{Kriptografi RSA}

RSA (Rivest-Shamir-Adelman) adalah algoritma kunci publik yang paling umum digunakan. RSA dapat digunakan baik untuk enkripsi pesan maupun untuk tanda tangan digital, makalah ini membahas RSA untuk enkripsi pesan. RSA umumnya aman bila kunci yang digunakan panjang (512 bit tidak aman, 768 bit cukup aman, 1024 bit 2048 bit aman). Semua algoritma kunci publik membutuhkan kunci yang sangat panjang, semakin panjang bit kunci semakin tinggi pula tingkat keamanannya.

Keamanan RSA bergantung pada kesulitan memfaktorkan bilangan integer besar menjadi faktor-faktor primanya. Algoritma RSA memiliki besaran-besaran sebagai berikut :

1. $\Phi(n)=(p-1)(q-1) \quad$ (rahasia)

2. $e$ (kunci enkripsi) (tidak rahasia)

3. $d$ (kunci dekripsi) (rahasia)

4. $m$ (plainteks) (rahasia)

5. $c$ (cipherteks) (tidak rahasia)

\section{Pembangkit kunci RSA}

1. Pilih 2 bilangan prima besar seperti $p, q$ dimana $p$ tidak sama dengan $q$.

2. Hitung $n=p \times q$

3. Hitung $\Phi(n)=(p-1) *(q-1)$

4. Pilih $\boldsymbol{e}$ yang relatif prima terhadap $\Phi(n)$

Relatif prima terhadap $\Phi(n)$ artinya faktor pembagi terbesar keduanya adalah 1, secara 
matematis dinotasikan $\operatorname{gcd}(e, \Phi(n))$ $=1$.

5. Hitung $\boldsymbol{d}$ integer sehingga $e^{*} d=1$ $\bmod n$ atau $(1+m \cdot n) / e$.

\section{Algortima Enkripsi dan Dekripsi RSA}

Enkripsi :

1. Ambil kunci publik penerima pesan $e$ dan modulus $n$

2. Nyatakan plainteks $m$ menjadi blokblok $m_{1}, m_{2}, \ldots$, sedemikian sehingga setiap blok merepresentasikan nilai di dalam selang [0,n -1].

3. Setiap blok $m_{i}$ dienkripsi menjadi blok $C i$ dengan rumus :

$C_{i}=m_{i}^{e} \bmod n$

Dekripsi :

Setiap blok cipherteks $C_{i}$ didekripsi kembali menjadi blok $m_{i}$ dengan rumus :

$$
M_{i}=C_{i}^{d} \bmod n
$$

\section{Kriptografi El Gamal}

Sistem kriptografi ElGamal ditemukan pada tahun 1984 oleh Taher ElGamal. Algoritma ini pada mulanya digunakan untuk digital signature, namun kemudian dimodifikasi sehingga juga bisa digunakan untuk enkripsi dan dekripsi. Keamanan algoritma ElGamal terletak pada sulitnya menghitung logaritma diskrit.

Besaran-besaran yang digunakan di dalam algoritma ElGamal adalah :

1. Bilangan prima, $p$

(tidak rahasia)

2. Bilangan acak, $\alpha(\alpha<p) \quad$ (tidak rahasia)

3. Bilangan acak, $d(d<p)$ (rahasia, kunci privat)

4. $\beta=\alpha^{d} \bmod p \quad$ (tidak rahasia, kunci publik)

5. $P$ (plainteks) (rahasia)

6. $c 1$ dan $c 2$ (cipherteks) (tidak rahasia) Langkah-langkah yang dilakukan dalam pembangkit kunci adalah
1. Memilih sebuah bilangąn prima $p$ untuk membentuk grup perkalian $\left(\mathrm{Z}_{\mathrm{p}}, \mathrm{x}\right)$. Kemudian pilih akar primitif

2. Pilih akar primitif $\alpha$ pada $\left(\mathrm{Z}_{\mathrm{p}}, \mathrm{x}\right) . \alpha$ merupakan akar primitif pada $\left(\mathrm{Z}_{\mathrm{p}}\right.$, $\mathrm{x})$ bila order $\alpha$ dinotasikan $\alpha=p-1$.

3. Pembangkit kunci memilih sebuah bilangan integer $d$ yang memenuhi 1 $<d<p-2$ dan menghitung $\beta=\alpha^{d}$ $\bmod p$

4. Kemudian menetapkan kunci publik $K_{\text {publik }}=(p, \alpha, \beta)$, dan kunci privat $K_{\text {privat }}=d$

\section{Algoritma Pembangkitan Kunci ElGamal}

1. Pilih bilangan prima $p$ besar sebagai basis grup perkalian $\left(\mathrm{Z}_{\mathrm{p}}, \mathrm{x}\right)$

2. Pilih $\alpha$ sebagai akar primitif pada $\operatorname{grup}\left(Z_{p}, x\right)$

3. Pilih $d$ yang memenuhi $1 \leq d \leq p-2$

4. Hitung $\beta=\alpha^{d} \bmod p$

5. $K_{\text {publik }}=(p, \alpha, \beta), K_{\text {privat }}=d$

\section{Algoritma Ekripsi dan Dekripsi ElGamal}

Enkripsi :

Input: $\mathrm{K}_{\text {publik }}=(p, \alpha, \beta) \stackrel{*}{\mathrm{P}} \in \mathrm{Z}_{\mathrm{p}}$

Output : $\mathrm{C}_{1}, \mathrm{C}_{2} \mathrm{Z}_{\mathrm{n}}$

$r \leftarrow \mathrm{Z}_{\mathrm{n}}\{\mathrm{r}$ dipilih acak $\}$

$C_{1}=\alpha^{r} \bmod p$

$C_{2}=\left(P \times \beta^{r}\right) \bmod p$

Dekripsi :

Input : $\mathrm{K}_{\text {private }}=d, C 1, C 2 \in \mathrm{Z}_{\mathrm{p}}$

Output : $P \in \mathrm{Z}_{\mathrm{n}}$

$P=\left[C_{2} \times C_{1}^{d}\right]^{-1} \bmod p$

Untuk membangkitkan kunci publik pada kriptografi RSA digunakan bilangan prima sebagai parameternya. Bilangan prima yang disarankan adalah bilangan prima yang berukuran besar, terdiri lebih dari seratus angka. LCG secara teoritis mampu menghasilkan bilangan acak yang baik, akan tetapi hal ini sangat bergantung pada pemilihan nilai $a, b$ dan $m$. Pemilihan 
nilai-nilai yang buruk dapat mengarah pada implementasi LCG yang tidak efisien. LCG mampu menghasilkan bilangan acak sesuai batasan nilai dan iterasi, keprimaannya dapat diuji dengan algoritma Miller-Rabin.

Langkah pertama yang dilakukan dalam pengujian ini adalah membangkitkan bilangan acak sebanyak $n$ bilangan dengan menggunakan algoritma LCG sesuai dengan persamaan (1), disarankan untuk menggunakan nilai a, b dan $m$ berdasarkan tabel 2 .

Misalnya, nilai a, b dan $\mathrm{m}$ yang dipilih adalah :

$$
\begin{aligned}
& a=106, b=1283, m=6075 \\
& X_{n}=\left(106 . X_{n-1}+1283\right) \bmod 6075 ; X_{0}=0
\end{aligned}
$$

Setelah dilakukan pengujian sebanyak 250 iterasi, tidak ditemukan adanya periode perulangan LCG, seperti pada gambar 1 . Langkah berikutnya adalah menguji keprimaan bilangan-bilangan acak yang dihasilkan LCG dengan menggunakan algoritma Miller-Rabin. Setelah dilakukan pengujian diperoleh bilangan-bilangan

\begin{tabular}{|c|c|c|c|}
\hline$e r=1$, & $1 \mathrm{cg}=1283$ & it er $=66, \log =5703$ & iter $=131, \operatorname{lcg}=2998$ \\
\hline it er $=2$, & $1 \mathrm{cg}=3631$ & iter $=67,1 \mathrm{cg}=4376$ & iter $=132,1 \mathrm{cg}=3171$ \\
\hline it er $=3$, & $\operatorname{lcg}=3444$ & it er $=68, \log =3439$ & iter $=133,1 \mathrm{cg}$ \\
\hline iter $=4$, & $\operatorname{lcg}=1847$ & iter $=69, \log =1317$ & It er $=134,1 \mathrm{cg}=3112$ \\
\hline it er $=5$, & $\operatorname{leg}=2665$ & it er $=70, \log =1160$ & iter $=135, \operatorname{lcg}=3105$ \\
\hline it er $=6$, & $1 \mathrm{cg}=4323$ & it er $=71, \quad \mathrm{cg}=2743$ & it er $=136,1 \mathrm{cg}$ \\
\hline iter $=7$, & $\operatorname{lcg}=3896$ & iter $=72, \log =441$ & iter $=137,1 \mathrm{cg}$ \\
\hline it er $=8$, & $\operatorname{leg}=1159$ & it er $=73,1 \mathrm{cg}=5504$ & iter $=138, \mathrm{lcg}=474$ \\
\hline iter $=9$, & $1 \mathrm{cg}=2637$ & iter $=74, \quad \log =1507$ & iter $=139,1 \mathrm{cg}$ \\
\hline it er $=10$, & $1 \mathrm{cg}=1355$ & it er $=75, \quad \log =3075$ & iter $=140, \quad \mathrm{cg}=1720$ \\
\hline it er $=11$, & $1 \mathrm{cg}=5188$ & it er $=76, \quad \mathrm{lgg}=5258$ & it er $=141,1 \mathrm{cg}$ \\
\hline iter $=12$, & $1 \mathrm{cg}=4461$ & it er $=77, \log =5806$ & iter $=142,1 \mathrm{cg}$ \\
\hline it er $=13$, & $1 \mathrm{cg}=299$ & it er $=78, \quad \mathrm{cg}=3144$ & it er $=143,1 \mathrm{cg}$ \\
\hline iter $=14$, & $1 \mathrm{cg}=2602$ & it er $=79, \mathrm{log}=422$ & iter $=144, \mathrm{lcg}$ \\
\hline it er $=15$, & $1 \mathrm{cg}=3720$ & it er $=80,1 \mathrm{cg}=3490$ & it er $=145,1 \mathrm{cg}$ \\
\hline iter $=16$, & $1 \mathrm{cg}=728$ & iter $=81, \quad \log =648$ & iter $=146,1 \mathrm{cg}=4243$ \\
\hline it er $=17$, & $1 \mathrm{cg}=5551$ & it er $=82, \log =3146$ & it er $=147, \quad \mathrm{cg}=1491$ \\
\hline it er $=18$, & $\operatorname{lcg}=414$ & it er $=83, \operatorname{lcg}=634$ & it er $=148,1 \mathrm{cg}=1379$ \\
\hline it er $=19$, & $1 \mathrm{cg}=2642$ & it er $=84, \log =1662$ & iter $=149,1 \mathrm{cg}=1657$ \\
\hline it er $=20$, & $\operatorname{lcg}=1885$ & it er $=85, \quad \log =1280$ & it er $=150,1 \mathrm{cg}=750$ \\
\hline it er $=21$, & $1 \mathrm{cg}=618$ & iter $=86, \log =3313$ & iter $=151, \operatorname{lcg}=1808$ \\
\hline it er $=22$, & $1 \mathrm{cg}=6041$ & it er $=87, \log =111$ & it er $=152, \quad 1 \mathrm{cg}=4606$ \\
\hline iter $=23$, & $1 \mathrm{cg}=3754$ & iter $=88, \log =899$ & it er $=153,1 \mathrm{cg}=3519$ \\
\hline iter $=24$, & $1 \mathrm{cg}=4332$ & it er=89, $\mathrm{lcg}=5452$ & iter $=154, \quad \mathrm{cg}=3722$ \\
\hline it er $=25$, & $1 \mathrm{cg}=4850$ & it er $=90, \quad \operatorname{lcg}=2070$ & iter $=155,1 \mathrm{cg}=940$ \\
\hline it er $=26$, & $1 \mathrm{cg}=5083$ & it er $=91,1 \mathrm{cg}=2003$ & it er $=156,1 \mathrm{cg}=3723$ \\
\hline iter $=27$, & $1 \mathrm{cg}=5481$ & it er $=92,1 \mathrm{cg}=976$ & iter $=157, \mathrm{lcg}=1046$ \\
\hline it er $=28$, & $1 \mathrm{cg}=5144$ & it er $=93, \mathrm{log}=1464$ & iter $=158,1 \mathrm{cg}=2809$ \\
\hline it er $=29$, & $1 \mathrm{cg}=5872$ & it er $=94, \quad \log =4592$ & iter $=159, \quad \mathrm{lcg}=1362$ \\
\hline iter $=30$, & $1 \mathrm{cg}=4065$ & it er $=95, \log =2035$ & iter $=160, \operatorname{lcg}=5930$ \\
\hline it er $=31$, & $1 \mathrm{cg}=848$ & it er $=96,1 \mathrm{cg}=4368$ & it er $=161,1 \mathrm{cg}=4138$ \\
\hline iter $=32$, & $1 \mathrm{cg}=46$ & it er $=97, \log =2591$ & iter $=162,1 \mathrm{cg}=2511$ \\
\hline it er $=33$, & $1 \mathrm{cg}=84$ & it er $=98,1 \mathrm{cg}=2554$ & it er $=163,1 \mathrm{cg}=149$ \\
\hline it er $=34$, & $1 \mathrm{cg}=4112$ & it er $=99, \log =4707$ & iter $=164, \mathrm{lcg}=4927$ \\
\hline it er $=35$, & $1 \mathrm{cg}=5830$ & it er $=100,1 \mathrm{cg}=2075$ & iter $=165, \quad \mathrm{cg}=1095$ \\
\hline it er $=36$, & $1 \mathrm{cg}=5688$ & it er $=101,1 \mathrm{cg}=2533$ & iter $=166,1 \mathrm{cg}$ \\
\hline it er $=37$, & $1 \mathrm{cg}=2786$ & it er $=102,1 \mathrm{cg}=2481$ & iter $=167, \mathrm{lcg}=5176$ \\
\hline iter $=38$, & $1 \mathrm{cg}=4999$ & it ex $=103,1 \mathrm{cg}=3044$ & iter $=168,1 \mathrm{cg}=3189$ \\
\hline it er $=39$, & $\operatorname{leg}=2652$ & it er $=104,1 \mathrm{cg}=1972$ & it er $=169,1 \mathrm{cg}$ \\
\hline it er $=40$, & $1 \mathrm{cg}=2945$ & it er $=105,1 \mathrm{cg}=3765$ & iter $=170, \quad 1 \mathrm{cg}=4885$ \\
\hline it er $=41$, & $\operatorname{lcg}=3628$ & iter $=106,1 \mathrm{cg}=5498$ & iter $=171,1 \mathrm{cg}=2718$ \\
\hline it er $=42$, & $1 \mathrm{cg}=3126$ & it er $=107,1 \mathrm{cg}=871$ & iter $m 172$, lcg $=3866$ \\
\hline iter $=43$, & $1 \mathrm{cg}=4589$ & it er $=108,1 \mathrm{cg}=2484$ & iter $=173,1 \mathrm{cg}$ \\
\hline iter $=44$, & $1 \mathrm{cg}=1717$ & iter $=109,1 \mathrm{cg}=3362$ & iter $=174, \quad \operatorname{lcg}=5757$ \\
\hline it er $=45$, & $1 \mathrm{cg}=1035$ & it er $=110,1 \mathrm{cg}=5305$ & iter $=175, \quad 1 \mathrm{cg}=4025$ \\
\hline iter $=46$, & $\operatorname{lcg}=1643$ & it er $=111,1 \mathrm{cg}=4713$ & it er $=176,1 \mathrm{cg}$ \\
\hline it er $=47$, & $1 \mathrm{cg}=5341$ & it er $=112,1 \mathrm{cg}=2711$ & it er $=177, \quad \mathrm{lcg}=156$ \\
\hline it er $=48$, & $1 \mathrm{cg}=2454$ & iter $=113,1 \mathrm{cg}=3124$ & iter $=178, \quad$ lcg $=5669$ \\
\hline it er $=49$, & $1 \mathrm{eg}=182$ & it er $=114,1 \mathrm{cg}=4377$ & it er $=179,1 \mathrm{cg}$ \\
\hline iter $=50$, & $1 \mathrm{cg}=2350$ & iter $=115,1 \mathrm{cg}=3545$ & it $=180, \mathrm{lcg}=4140$ \\
\hline iter $=51$, & $1 \mathrm{cg}=1308$ & it er $=116,1 \mathrm{cg}=403$ & iter $=181,1 \mathrm{cg}=2723$ \\
\hline it er $=52$, & $1 \mathrm{cg}=206$ & iter $=117,1 \mathrm{cg}=1476$ & iter $=182,1 \mathrm{cg}$ \\
\hline iter $=53$, & $1 \mathrm{cg}=4894$ & it er $=118,1 \mathrm{cg}=5864$ & iter $=183, \mathrm{lcg}=5559$ \\
\hline it er $=54$, & $1 \mathrm{cg}=3672$ & it er $=119,1 \mathrm{cg}=3217$ & it er $=184,1 \mathrm{cg}$ \\
\hline iter $=55$, & $1 \mathrm{cg}=1715$ & iter $=120,1 \mathrm{cg}=2085$ & iter $=185, \mathrm{lcg}$ \\
\hline it er $=56$, & $1 \mathrm{cg}=823$ & it er $=121,1 \mathrm{eg}=3593$ & it ex $=186,1 \mathrm{cg}$ \\
\hline iter $=57$, & $1 \mathrm{cg}=3471$ & iter $=122,1 \mathrm{cg}=5491$ & iter $=187,1 \mathrm{cg}=1286$ \\
\hline iter $=58$, & $1 \mathrm{cg}=4709$ & it er $=123,1 \mathrm{cg}=129$ & iter $=188, \quad$ lcg $=3949$ \\
\hline it er $=59$, & $1 \mathrm{cg}=2287$ & iter $=124,1 \mathrm{cg}=2807$ & iter $=189, \mathrm{lcg}$ \\
\hline iter $=60$, & $1 \mathrm{cg}=705$ & it er $=125,1 \mathrm{cg}=1150$ & iter $=190, \mathrm{lcg}=2795$ \\
\hline it er $=61$, & $1 \mathrm{cg}=3113$ & it er $=126,1 \mathrm{cg}=1683$ & iter $=191, \quad 1 \mathrm{cg}=5953$ \\
\hline it er $=62$, & $1 \mathrm{cg}=3211$ & it er $=127, \operatorname{lcg}=3506$ & it er $=192,1 \mathrm{cg}$ \\
\hline iter $=63$, & $1 \mathrm{cg}=1449$ & it er $=128,1 \mathrm{cg}=2344$ & iter $=193,1 \mathrm{cg}$ \\
\hline & $\operatorname{lcg}=3002$ & it er $=129$, & iter $=194,1 \mathrm{cg}$ \\
\hline it er $=65$, & $1 \mathrm{cg}=3595$ & it er $=130,1 \mathrm{cg}=5690$ & it er $=195, \quad \mathrm{cg}=3810$ \\
\hline
\end{tabular}
prima seperti terlihat pada gambar 1 . 
Gambar 1. Bilangan hasil algoritma LCG dan bilangan prima hasil algoritma Miller-Rabin

Kemudian diseleksi dua bilangan prima yang bernilai besar untuk dijadikan nilai p dan q pada kriptografi RSA, dan nilai p pada kriptografi ElGamal.

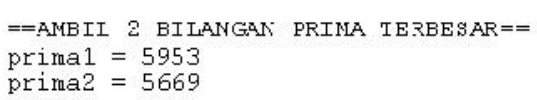

Selanjutnya kedua bilangan prima tersebut diimplementasi untuk merancang pembangkitan kunci publik pada algoritma RSA dan algoritma ElGamal. Implementasi pembangkitan kunci publik RSA sebagai berikut :

1. $p=5953$

$q=5669$

nilai $p$ dan $q$ dipilih dari bilangan prima yang dihasilkan pembangkitan bilangan acak di atas.

Berdasarkan algoritma pembangkitan pasangan kunci RSA di atas, diperoleh hasil sebagai berikut :

2. $n=5953 \times 5669$

$n=33747557$

3. $\Phi(n)=(\mathrm{p}-1) \times(\mathrm{q}-1)$

$\Phi(n)=(5953-1) \times(5669-1)$

$\Phi(n)=33735936$

4. Menghitung $e$ bilangan relatif prima terhadap $n$.

$e=5$, maka $\operatorname{gcd}(5,33735936)=1$

5. Menghitung $d$ dimana, e.d $\bmod \Phi(n)$

$=1$

$d=26988749$, karena

$5 \times 26988749 \bmod 33735936=1$

Dari perhitungan tersebut diperoleh kunci publik $(5,33747557)$ dan kunci privat (26988749, 33747557). Kunci publik dan kunci privat ini akan digunakan untuk proses enkripsi dan dekripsi pada RSA sebagai berikut :
Misal pesan adalah 'HUJAN'

\begin{tabular}{|l|l|l|l|l|l|}
\hline Pesan & H & U & J & A & N \\
\hline ASCII & 72 & 85 & 74 & 65 & 78 \\
\hline
\end{tabular}

Plainteks : 7285746578

Kemudian dipecah menjadi 4 blok

Plainteks :

\begin{tabular}{l|c|c|c|c|}
\hline Pesan & 728 & 574 & 657 & 008 \\
\hline$C 1=728^{5} \bmod 33747557=27155095$ \\
$C 2=5745 \bmod 33747557=4861433$ \\
$C 3=657^{5} \bmod 33747557=21008501$ \\
$C 4=008^{5} \bmod 33747557=32768$
\end{tabular}

Hasil enkripsi menjadi :

\begin{tabular}{|l|l|l|l|l|}
\hline Ciphertek & 2715509 & 486143 & 2100850 & 3276 \\
s & 5 & 3 & 1 & 8 \\
\hline
\end{tabular}

Selanjutnya cipherteks tersebut didekripsi agar kembali ke pesan aslinya dengan menggunaan kunci privat sebagai berikut :

$P 1=2715509526988749 \bmod 33747557=$ 728

$P 2=486143326988749 \bmod 33747557=$ 574

$P 3=2100850126988749 \bmod 33747557=$ 657

$P 4=32768^{26988749} \bmod 33747557=8$

Hasil dekripsi menjadi :

\begin{tabular}{|l|l|l|l|l|}
\hline Plainteks & 728 & 574 & 657 & 8 \\
\hline
\end{tabular}

Kemudian pesan tersebut disatukan kembali menjadi :

Pesan : 7285746578

Sehingga dihasilkan :

\begin{tabular}{|l|l|l|l|l|l|}
\hline ASCII & 72 & 85 & 74 & 65 & 78 \\
\hline Pesan : & $\mathrm{H}$ & $\mathrm{U}$ & $\mathrm{J}$ & $\mathrm{A}$ & $\mathrm{N}$ \\
\hline \multicolumn{7}{|c|}{ Selanjutnya implementasi prima }
\end{tabular}

tersebut untuk pembangkitan kunci ElGamal sebagai berikut:

Prima yang dipilih adalah prima besar yang dihasilkan dari pembangkitan bilangan acak sebelumnya, dimana

1. $p=5953$

2. Pilih $\alpha$ sebagai akar primitif pada $\left(\mathrm{Z}_{\mathrm{p}, \mathrm{X}}^{*}\right)$ 


$$
\alpha=4365
$$

3. Pilih sebuah bilangan integer acak $d$ yang memenuhi $1 \leq d \leq p-2$. Maka nilai $d=4680$

4. $\beta=4365^{4680} \bmod 5953, \beta=1316$

5. Maka diperoleh kunci publik = $(5953,4365,1316)$ dan kunci privat $=(4680)$

Kunci publik dan kunci privat ini akan digunakan untuk proses enkripsi pada ElGamal. Berdasarkan algoritma enkripsi dan dekripsi ElGamal diperoleh hasil sebagai berikut :

1. Kunci $_{\text {publik }}=(5953,4365,1316)$

2. $r$ dipilih secara acak, maka nilai $r=$ 1597

3. $C_{1}=4365^{1597} \bmod 5953$

$C_{1}=3778$

4. Menghitung nilai $C_{2}$ sebagai berikut :

\begin{tabular}{|l|l|l|l|}
\hline Teks & ASCII & \multicolumn{1}{|c|}{$C_{2}$} \\
\hline $\mathrm{H}$ & 72 & $\begin{array}{l}\left(72 * 1316^{1597}\right) \bmod 5953= \\
262\end{array}$ \\
\hline $\mathrm{U}$ & 85 & $\begin{array}{l}\left(85^{*} 1316^{1597}\right) \bmod 5953= \\
2459\end{array}$ \\
\hline $\mathrm{J}$ & 74 & $\begin{array}{l}\left(74^{*} 1316^{1597}\right) \bmod 5953= \\
600\end{array}$ \\
\hline $\mathrm{A}$ & 65 & $\begin{array}{l}\left(65 * 1316^{1597}\right) \bmod 5953= \\
5032\end{array}$ \\
\hline $\mathrm{N}$ & 78 & $\begin{array}{l}\left(78 * 1316^{1597}\right) \bmod 5953= \\
1276\end{array}$ \\
\hline
\end{tabular}

Hasil enkripsi menjadi :

\begin{tabular}{|c|c|c|c|c|c|}
\hline Cipherteks & 262 & 2459 & 600 & 5032 & 1278 \\
\hline Selanjutnya & \multicolumn{3}{|c|}{ cipherteks } & tersebut
\end{tabular}
didekripsi agar kembali ke pesan aslinya dengan menggunaan kunci privat sebagai berikut :

1. Kunci $_{\text {private }}=(4680)$

2. Menghitung nilai $P$ sebagai berikut :

\begin{tabular}{|c|l|}
\hline$C_{2}$ & \multicolumn{1}{|c|}{$P$} \\
\hline 262 & $\begin{array}{l}262 \times 3778^{5953-1-4680} \bmod 5953= \\
72\end{array}$ \\
\hline 2459 & $\begin{array}{l}2459 \times 3778^{5953-1-4680} \bmod 5953= \\
85\end{array}$ \\
\hline 600 & $\begin{array}{l}600 \times 3778^{5953-1-4680} \bmod 5953= \\
74\end{array}$ \\
\hline 5032 & $\begin{array}{l}5032 \times 3778^{5953-1-4680} \bmod 5953= \\
65\end{array}$ \\
\hline 1276 & $\begin{array}{l}1278 \times 3778^{5953-1-4680} \bmod 5953= \\
78\end{array}$ \\
\hline
\end{tabular}

Hasil dekripsi menjadi :

\begin{tabular}{|c|c|c|c|c|c|}
\hline Plainteks & 72 & 85 & 74 & 65 & 78 \\
\hline \multicolumn{6}{|c|}{ Sehingga dihasilkan : } \\
\hline ASCII & 72 & 85 & 74 & 65 & 78 \\
\hline Pesan : & $\mathrm{H}$ & $\mathrm{U}$ & $\mathrm{J}$ & A & $\mathrm{N}$ \\
\hline
\end{tabular}

\section{SIMPULAN}

Dari hasil pengujian dan analisis sebelumnya, dapat disimpulkan bahwa, LCG mampu menghasilkan bilangan acak yang efisien dengan memperhatikan penggunaan nilai untuk parameter $a, b$ dan $m$. Algoritma Miller-Rabin memiliki komputasi yang ringan dan memberikan nilai probabilitas yang tinggi untuk menguji keprimaan bilangan acak yang dihasilkan dari LCG. Algoritma RSA dan ElGamal dapat mengembalikan pesan yang telah dienkripsi dari hasil pemfaktoran bilangan prima yang sangat besar yang dihasilkan oleh LCG dan telah diuji menggunakan algoritma Miller-Rabin .

\section{DAFTAR PUSTAKA}

Munir, Rinaldi. 2006. Kriptografi. Informatika. Bandung.

Sadikin, Rifki. 2012. Kriptografi Untuk Keamanan Jaringan. Andi Offset. Yogyakarta.

Schneier, Bruce. 1996. Applied Cryptography Second Edition. John Wiley \& Sons.

Menezes, Alfred J., Paul C. van Oorschot \& Scott A. Vanstone. 2001. Hand Book of Applied Cripthography. CRC Press.

Mollin, Richard A. 2000. Fundamental Number Theory with Application. CRC Press.

Croft, Anthony., Davison, Robert. 2006. Foundation Maths. Ashford Colour Press. 